OPEN ACCESS

Edited by:

Francisco Jose Barba

University of Valencia, Spain

Reviewed by:

Fatih Öz,

Atatürk University, Turkey Kin Weng Kong,

University of Malaya, Malaysia

*Correspondence:

Stefania Marzorat

stefania.marzorati@unimi.it

Specialty section

This article was submitted to Food Chemistry,

a section of the journal

Frontiers in Nutrition

Received: 25 June 2021 Accepted: 06 August 2021 Published: 13 September 2021

Citation:

Marzorati S, Martinelli G, Sugni M and Verotta L (2021) Green Extraction Strategies for Sea Urchin Waste Valorization. Front. Nutr. 8:730747. doi: 10.3389/fnut.2021.730747

\section{Green Extraction Strategies for Sea Urchin Waste Valorization}

\author{
Stefania Marzorati ${ }^{\star}$, Giordana Martinelli, Michela Sugni and Luisella Verotta
}

Department of Environmental Science and Policy, Università degli Studi di Milano, Milan, Italy

Commonly known as "purple sea urchin," Paracentrotus lividus occurs in the Mediterranean Sea and the eastern Atlantic Ocean. This species is a highly appreciated food resource and Italy is the main consumer among the European countries. Gonads are the edible part of the animal but they represent only a small fraction (10-30\%) of the entire sea urchin mass, therefore, the majority ends up as waste. Recently, an innovative methodology was successfully developed to obtain high-value collagen from sea urchin by-products to be used for tissue engineering. However, tissues used for the collagen extraction are still a small portion of the sea urchin waste $(<20 \%)$ and the remaining part, mainly the carbonate-rich test and spines, are discarded. Residual cell tissues, tests, and spines contain polyunsaturated fatty acids, carotenoids, and a class of small polyphenols, called polyhydroxynaphthoquinones (PHNQ). PHNQ, due to their polyhydroxylated quinonoid nature, show remarkable pharmacologic effects, and have high economic significance and widespread application in several cosmetic and pharmaceuticals applications. A green extraction strategy aimed to obtain compounds of interest from the wastes of sea urchins was developed. The core strategy was the supercritical $\mathrm{CO}_{2}$ technique, characterized by low environmental impacts. Fatty acids and carotenoids were successfully and selectively extracted and identified depending on the physical parameters of the supercritical $\mathrm{CO}_{2}$ extraction. Finally, the exhausted powder was extracted by solvent-based procedures to yield PHNQ. The presence of Spinochrome A and Spinochrome B was confirmed and extracts were characterized by a remarkably high antioxidant activity, measured through the 2,2'-azino-bis(3ethylbenzothiazoline-6-sulfonic acid) (ABTS) assay. Overall, the selective and successive extraction methods were validated for the valorization of waste from sea urchins, demonstrating the feasibility of the techniques targeting added-value compounds.

Keywords: sea urchin's waste, biomass valorization, green extraction, supercritical $\mathrm{CO}_{2}$, antioxidants, polyhydroxylated naphtoquinones

\section{INTRODUCTION}

Food waste valorization implies its conversion into higher-value products that contribute back to the supply chain or other kinds of applications that support the circular economy approach where useful materials, once seen as waste or by-products, are recycled. Given the high interest in the environmental issues, already remarked by the 17 Sustainable and Development Goals of Agenda 2030, where sustainability is the core, nowadays a lot of research is ongoing in the field of food industrial sustainability during the production process and at the end of the chain (1). This points 
to ensure zero-waste strategies since both by-products and endproducts are granted a second life. The shift from a linear economy model to a circular one differs substantially in the perspective on sustainability, aiming to ensure healthy and safe living while causing less harm to the environment.

Within this context, sea urchins, belonging to the class Echinoidea of the echinoderm phylum, are a highly appreciated food resource. Indeed, around 75,000 tons of sea urchins are sold annually worldwide for gonads consumption and in recent decades, the demand for sea urchins is increasing $(2,3)$. Italy is the main consumer among the European countries with 30 million sea urchins annually consumed only in Sardinia (4). However, since the yellow-orange gonads are the only edible part, representing a small fraction of the entire animal, the remaining ends up as waste. Recently, an innovative methodology was successfully developed to obtain high-value collagen from sea urchin by-product tissues to be used for regenerative medicine applications (5). Prototypes of biodegradable medical devices made of this eco-friendly marine collagen were developed and characterized, analyzing their microstructure, mechanical performances, in vitro cytocompatibility, and, recently, also their regeneration efficiency in in vivo animal model (6-8). However, the tissues used for the collagen extraction are a small portion of sea urchin waste $(<20 \%)$, and the remaining part, mainly the carbonate-rich test and spines, would be discarded again.

The interest in this secondary waste, comprising both the residual tissues and tests and spines, is however still high, considering that marine organisms, such as sea urchins, have been widely studied for their richness in secondary metabolites, displaying potent activities and exciting pharmacological potential. Examples abound of antitumor, antiviral, immunosuppressive and antimicrobial agents, and cardiac stimulants (9). Several studies have indicated that the gonads of sea urchins are rich in important bioactive, such as polyunsaturated fatty acids, sterols, and carotenoids. An extract of gonad tissue has also revealed effective anti-inflammatory and anti-diabetic properties (10). Even more interesting, a class of small polyphenols characterized by a hydroxylated quinonoid chemical structure, identified as polyhydroxynapthoquinones (PHNQ), has been described, exhibiting a wide range of biological activities. More than 40 naphthoquinones have already been identified from different sea urchin species, Echinochrome A and the Spinochromes A-E are the best-known (11). They are generally derivatives of polyhydroxy-1,4-naphthoquinones, substituted with ethyl, acetyl, methoxy, or amino groups $(12,13)$. In addition to the presence of a chromophore that is responsible for the PHNQ characteristic colors, pigments have high economic significance because of their widespread applications as antibacterial and fungicidal agents. Furthermore, they have shown protection against UV-induced damage and their ability to scavenge the reactive oxygen species (ROS) pointed to their use as antioxidants or as an immune modulator $(14,15)$. Particularly, Echinochrome A was introduced as an active substance of the drug Histochrome, commonly used in ophtalmological and cardiological clinical practice in Russia (15).

Considering the high potential of the compounds present in sea urchins, this study aimed to develop extraction strategies resulting in the downstream processes able to exhaust the added value from this food waste. First, targeting the lipid content, a "green" extraction was developed, by means of supercritical carbon dioxide. This technology, employing $\mathrm{CO}_{2}$ as an extraction fluid is indeed characterized by low environmental impacts: organic solvents are avoided ensuring safe and selective processes directly on the powder without any pretreatment, with the possibility to recycle the employed $\mathrm{CO}_{2}$ in the industrial plants. In a second stage, a small percentage of ethanol, acting as a polarity modifier, was employed together with supercritical $\mathrm{CO}_{2}$ to target more polar compounds.

The absence of any excessive heating or destructive step allowed a further and final extraction, able to successfully yield PHNQ. The pigments were selectively and separately obtained from the previously extracted powder, their chemical structure was assigned, and their antioxidant activity was finally assessed.

\section{MATERIALS AND METHODS}

\section{Chemicals}

All chemicals were used without further treatment. Acetonitrile, methanol, and water, when used for liquid chromatography, were purchased from Merck (Germany) as ultra-performance liquid chromatography-grade. Anhydrous sodium sulfate, sodium carbonate, formic acid, ethanol, ethyl acetate, 2,2' azino-bis(3-ethylbenzothiazoline-6-sulfonic acid) $(\geq 98 \%$; ABTS), Folin-Ciocalteu reagent (2M), and 6-hydroxy-2,5,7,8tetramethylchroman-2-carboxylic acid (97\%; Trolox $\left.{ }^{\circledR}\right)$ were purchased from Merck (Germany). Gallic acid was purchased from Carbosynth (UK), astaxanthin, and lutein (90\%) from Acros Organics (Thermo Fisher, Germany), and $\beta$-carotene (99\%) from Alfa Aesar (Thermo Fisher, Germany). The silylation reagent (SILYL-991) was purchased from Macherey-Nagel (Germany).

\section{Starting Material}

In the study, $50 \mathrm{~kg}$ of wastes of sea urchins, belonging to the species identified as Paracentrotus lividus (origin: Adriatic Sea) were kindly donated from the restaurants close to the University of Milan after gonads removal and kept at $-20^{\circ} \mathrm{C}$. The recovered material was then lyophilized to eliminate the residual water (between 50 and $60 \%$ by weight of starting biomass) and better preserve the material. Lyophilization was conducted in $24 \mathrm{~h}$ using a 5Pascal Srl (Italy) freeze dryer equipment. The lyophilized material was then ground using a knife mill (Fritsch, Pulverisette 11, Italy), at 10,000 rpm for $20 \mathrm{~s}$. To avoid powder heating during blending and the consequent degradation of thermolabile species, liquid nitrogen was added.

\section{Supercritical Fluid Extractions}

Supercritical fluid extractions $\left(\mathrm{sc}-\mathrm{CO}_{2}\right)$ were performed using a pilot unit SFT110XW System supplied by Supercritical Fluid Technologies, Inc. (DE, USA). It consisted of a $100 \mathrm{~cm}^{3}$ stainless steel extraction vessel inserted in an oven, a constant pressure piston pump (SFT-Nex10 SCF Pump) with a Peltier Cooler, a 515 HPLC pump (Waters, Milford, MA, USA) for the co-solvent addition, and a collection vial. 
The extraction vessel was filled with a weighted amount of lyophilized and grounded sea urchins waste (about $60 \mathrm{~g}$ of powder was used in each trial). The system was sealed, and the oven and restrictor block temperatures were set at 60 and $75^{\circ} \mathrm{C}$, respectively. After a literature overview and optimization trials, the operative pressure was set as 200 bar in all experiments. Extractions were performed in triplicate.

Nine cycles, comprising $10 \mathrm{~min}$ of maceration time in static conditions and $30 \mathrm{~min}$ of dynamic conditions, were performed for the extraction experiment. In dynamic conditions, the valves were opened, and the extract was collected in a vial, keeping the $\mathrm{CO}_{2}$ gas at a constant flow rate of $15 \mathrm{SCFH}$ (standard cubic feet per hour). The extracts were then stored in a freezer for subsequent analyses.

To further extract the material, shifting the window of extractable compounds toward more polar targets, a subsequent extraction was performed on the same material using $\mathrm{sc}-\mathrm{CO}_{2}$ added with $10 \%$ of ethanol as co-solvent. $4.6 \mathrm{ml}$ of ethanol was loaded into the vessel before pressurization. Once the set pressure (200 bar) was reached and a static period of $10 \mathrm{~min}$ was maintained, valves were opened to collect the sample for $30 \mathrm{~min}$ in dynamic conditions. During the dynamic extraction, the first four cycles were performed using an ethanol flow rate of $0.5 \mathrm{ml} \mathrm{min}-1$, whereas the last three cycles were carried out with an ethanol flow rate of $1.5 \mathrm{ml} \mathrm{min}{ }^{-1}$. The vessel was then depressurized, and the residual biomass was collected. The sc$\mathrm{CO}_{2}$ extraction, in the presence of co-solvent, was run three times for sake of data reliability.

\section{PHNQ Extraction}

The PHNQ extraction from sc- $\mathrm{CO}_{2}$ extracted powder was carried out with modifications of the literature method by Powell et al. (16). Briefly, $140 \mathrm{ml}$ of $6 \mathrm{M}$ formic acid were added dropwise under stirring (at room temperature) to $20 \mathrm{~g}$ of sea urchin powder, exactly weighted, to decompose the carbonate matrix. The mixture was stirred for $1 \mathrm{~h}$. The suspension was centrifuged at 6,000 rpm for $5 \mathrm{~min}$, and the supernatant was further filtered under vacuum using the Büchner funnel. The acid aqueous extract was then counter-extracted with aliquots of $50 \mathrm{ml}$ of ethyl acetate. The orange/pink organic layers were separated, and the extraction process was repeated three times with fresh aliquots of ethyl acetate. Organic phases were collected and then washed repetitively with milli-Q water to remove the residual formic acid and inorganic salts. This step was repeated until the aqueous phase conductivity and $\mathrm{pH}$ were close to the milli-Q water ones. Approximately 10 washing cycles were necessary. Anhydrous sodium sulfate was added to remove the residual water in the organic phase. The extract was then dried by a rotary evaporator $\left(37^{\circ} \mathrm{C}\right)$ and finally by a mechanical vacuum pump.

\section{Total Phenolic Content (TPC)}

The total phenolic content was determined using the FolinCiocalteu assay. Following a literature method (17), $25 \mu \mathrm{l}$ of standard solutions of gallic acid (range $0-1 \mathrm{mg} \mathrm{ml}^{-1}$ ) were added with $1.5 \mathrm{ml}$ of deionized water and $125 \mu \mathrm{l}$ of FolinCiocalteu reagent (2M). After $5 \mathrm{~min}, 0.5 \mathrm{ml}$ of a $15 \% \mathrm{Na}_{2} \mathrm{CO}_{3}$ aqueous solution were added. After $2 \mathrm{~h}$ incubation in the dark, the absorbance was measured at $765 \mathrm{~nm}$ using Jasco V-630 Spectrophotometer (MD, USA). After building the gallic acid calibration line (plotting the gallic acid concentration vs. $A_{765 \mathrm{~nm}}$ ), the same method was performed on the methanolic solution of PHNQ. Results are expressed as mg GAE $g_{\text {PHNQextract }}^{-1}$ (GAE = gallic acid equivalents).

\section{ABTS Assay}

To evaluate the antioxidant activity of the product, the spectrophotometric analysis of $\mathrm{ABTS}^{\bullet+}$ radical scavenging activity was performed according to Loganayaki et al. (18). Briefly, a $7 \mathrm{mM}$ ABTS aqueous solution was prepared. Then, ABTS radical cation was produced by reacting ABTS aqueous solution with $2.45 \mathrm{mM}$ ammonium persulfate (final concentration) and allowing the mixture to stand in the dark at room temperature for $12-16 \mathrm{~h}$ before use. Prior to the assay, the solution was diluted in ethanol (about 1:75 v/v) to give an absorbance at $734 \mathrm{~nm}$ of 0.700 in a $1 \mathrm{~cm}$ cuvette. Different concentrations (in the range $0-0.012 \mathrm{mg} \mathrm{ml}^{-1}$ ) of the methanolic solutions of PHNQ extracts were reacted with the ABTS radical cation. The same procedure was carried out using different concentrations of Trolox ${ }^{\circledR}$ solutions. The blank did not contain the sample. After $1 \mathrm{~h}$ incubation in the dark, the absorbance was measured at $734 \mathrm{~nm}$. The extract concentration in solution was plotted vs. the percentage of $\mathrm{ABTS}^{\bullet+}$ remaining in solution, calculated as in Equation 1:

$$
\% \mathrm{ABTS}^{\bullet+} \text { remaining }=\frac{A_{734 \mathrm{~nm}, 1 \mathrm{~h}, \text { sample }}}{A_{734 \mathrm{~nm}, 1 \mathrm{~h}, \text { blank }}} \%
$$

Extract and Trolox ${ }^{\circledR} \quad \mathrm{EC}_{50}$ values were read on the graph. Experiments were performed three times.

\section{Characterization}

\section{Inductively Coupled Plasma Optical Emission Spectrometry (ICP-OES)}

In the study, $\mathrm{Ca}^{2+}$ and $\mathrm{Mg}^{2+}$ contents in sea urchin waste were quantified by weight using ICP-OES. Before analysis, the powder of sea urchins was decomposed by the treatment with $6 \mathrm{M}$ formic acid. The residual solid was filtered by the Buchner funnel and then by $0.22 \mu \mathrm{m}$ PTFE syringe filters. The filtered solution was diluted and then analyzed by using Perkin Elmer Optima 8000 equipment (MA, USA). A 5-points calibration line was built for both elements in the range $2.5-20 \mathrm{mg} \mathrm{L}^{-1}$; Wavelengths: Ca: $317.933 \mathrm{~nm}, \mathrm{Mg}$ : $285.213 \mathrm{~nm}$; Plasma: $10 \mathrm{~L} \mathrm{~min}^{-1}$; auxiliary gas: $0.2 \mathrm{~L} \mathrm{~min}{ }^{-1}$; nebulizer (Meinhard K1, Perkin Elmer): $0.55 \mathrm{~L}$ $\min ^{-1}$; peristaltic pump: $1 \mathrm{ml} \mathrm{min}^{-1}$.

\section{Gas Chromatography-Mass Spectrometry (GC-MS)}

Before the GC-MS analyses, samples were subjected to a derivatization process. A modification of a literature method was used (19). Briefly, about $5 \mathrm{mg}$ of each sample were accurately weighed, suspended in $100 \mu l$ of anhydrous pyridine, and silylated using $100 \mu \mathrm{l}$ of $\mathrm{N}, \mathrm{O}-\mathrm{Bis}$ (trimethylsilyl)trifluoroacetamide (BSTFA) containing $1 \%$ of Trimethylsilyl chloride (TMCS). The samples were incubated at $60^{\circ} \mathrm{C}$ and stirred for $2 \mathrm{~h}$. At the end of the reaction, $0.8 \mathrm{ml}$ of ethyl acetate was added. The samples were then filtered $(0.22 \mu \mathrm{m}$ 
PTFE syringe filters) and analyzed by using an ISQ ${ }^{\mathrm{TM}}$ QD Single Quadrupole GC-MS (Thermo Fisher, MA, USA) equipped with a VF-5ms $(30 \mathrm{~m} \times 0.25 \mathrm{~mm}$ i.d. $\times 0.25 \mu \mathrm{m}$; Agilent Technology, CA, USA). Injection volume: $1 \mu \mathrm{l}$, split mode; Oven program: $120^{\circ} \mathrm{C}$ for $5 \mathrm{~min}$; then $10^{\circ} \mathrm{C} \mathrm{m^{-1 }}$ to $200^{\circ} \mathrm{C}$; $5 \mathrm{~min}$ holding time; then $20^{\circ} \mathrm{C} \mathrm{m^{-1 }}$ to $300^{\circ} \mathrm{C} ; 15 \mathrm{~min}$ holding time; $\mathrm{C}$ for $15 \mathrm{~min}$; run time: $38 \mathrm{~min}$. Helium was used as a gas carrier. Ionization mode: electron impact: $-70 \mathrm{eV}$. Acquisition mode: full scan. To identify the chemical structure of the species eluting, the fragmentation pattern of each peak was compared to NIST 2014 database.

\section{Ultrahigh-Performance Liquid Chromatography-Tunable Ultraviolet-Electrospray Ionization-Mass Spectrometry (UPLC-TUV-ESI-MS)}

The identification and quantification of carotenoids, by comparison to authentic standards (when available) was performed on Acquity UPLC equipment (Waters corp., MA, USA), and the following conditions were used: column: ACQUITY UPLC BEH C $18(50 \times 2.1 \mathrm{~mm}, 1.7$ um) (Waters, Milford, MA, USA), column temperature: $34^{\circ} \mathrm{C}$, and eluents were $\mathrm{A}$ : water $+0.1 \%$ formic acid and $\mathrm{B}$ : acetonitrile $+0.1 \%$ formic acid. The flow rate was set at $0.3 \mathrm{ml} \mathrm{min}-1$ and the linear gradient elution was: START: $25 \%$ A: $75 \%$ B; 20 min: $0 \% \mathrm{~A}: 100 \% \mathrm{~B} ; 28 \mathrm{~min}: 0 \% \mathrm{~A}: 100 \% \mathrm{~B}$; the sample temperature was kept constant at $20^{\circ} \mathrm{C}$ and the injection volume was $2 \mu \mathrm{l}$. Injections have been repeated three times. The detector was an Acquity TUV Detector (Waters, Milford, MA, USA), and the wavelength was set at $445 \mathrm{~nm}$. Data were processed with Empower 3 workstations. Limit of detection (LOD) and limit of quantification (LOQ) were calculated according to Ermer et al. (20). Chromatographic separation was followed by a mass spectrometry (LCQ Fleet Thermofisher, MA, USA) analysis, according to a previous study (21). A positive electrospray mode was used for the ionization of molecules with a capillary voltage of $50 \mathrm{~V}$ and at a capillary temperature of $275^{\circ} \mathrm{C}$. The heater temperature was set at $40^{\circ} \mathrm{C}$, the gas flow rate was 20 (arb), and the spray voltage was $4.0 \mathrm{kV}$. The monitored mass range was $m / z$ 100-900.

\section{Ultrahigh Performance Liquid Chromatography-Photodiode Array-Electrospray Ionization-High Resolution Mass Spectrometry (UPLC-PDA-ESI-HRMS)}

The identification of the PHNQs in the extract was carried out using UPLC-PDA-ESI-HRMS. The UPLC-PDA-ESI-HRMS analyses were performed by the Unitech COSPECT Mass Spectrometry facility (University of $<$ city $>$ Milan $<$ /city $>$, Italy). The UPLC equipment was Acquity UPLC I Class (Waters, Milford, MA, USA), and the following conditions were used: column: ACQUITY UPLC BEH $\mathrm{C}_{18}(50 \times 2.1 \mathrm{~mm}, 1.7 \mathrm{um})$ (Waters, USA), column temperature: $34^{\circ} \mathrm{C}$, and eluents were A: water $+0.1 \%$ formic acid and B: acetonitrile $+0.1 \%$ formic acid. The flow rate was set at $0.5 \mathrm{ml} \mathrm{min}-1$ and the linear gradient elution was set: START: 95\% A: 5\% B; 5.15 min: 60\% A: 40\% B; 6 min: $10 \%$ A: $90 \%$ B; $6.30 \mathrm{~min}: 10 \%$ A: $90 \%$ B; $6.60 \mathrm{~min}: 95 \%$ A: $5 \% \mathrm{~B} ; 10 \mathrm{~min}: 95 \% \mathrm{~A}: 5 \% \mathrm{~B}$. The sample temperature was kept constant at $20^{\circ} \mathrm{C}$ and the injection volume was $4 \mu \mathrm{l}$. The detector was an Acquity UPLC PDA Detector (Waters, Milford, MA, USA) working in a wavelength range of $210-500 \mathrm{~nm}$. The HRMS detector was a Synapt G2-Si QTof (Waters, USA). The operative parameters are given in the following: ESI Ionization mode, negative ionization polarity, full scan range $50-1,200 \mathrm{~m} / z$, leucine enkephalin was the lock mass compound. The used software was MassLynxTM v4.2 (Waters, Milford, MA, USA).

\section{RESULTS}

\section{Supercritical $\mathrm{CO}_{2}$ Extractions Pure Supercritical $\mathrm{CO}_{2}$}

Figure 1A displays the kinetics of extraction when the supercritical $\mathrm{CO}_{2}$ extraction was run on the pristine sea urchin powder. Each point represents the incremental yield (\% g extract $/ g$ dry biomass), detected over time and hence over $\mathrm{CO}_{2}$ consumption. The alternation of static and dynamic cycles was interrupted when the incremental yield reached a plateau, indicating no more evident extracted mass increment. This ending point was reached after 750 liters of gaseous $\mathrm{CO}_{2}$ have been consumed, corresponding to $270 \mathrm{~min}$ of extraction in the dynamic conditions. The inset in Figure 1A shows the appearance of the oily extract, characterized by brilliant orange color. The final yield corresponded to $0.34 \pm 0.02 \%$ by dry weight of the starting biomass.

The obtained sample was characterized by GC-MS, after BSTFA/TMS derivatization to get the corresponding silyl derivatives. The fatty acid composition is displayed in Table $\mathbf{1}$ and the GC-MS chromatogram displaying the total ion current is shown in Figure 2. The most intense peak is attributed to cholesterol [peak 8, r.t (retention time) $=27.22 \mathrm{~min}$ ]. Due to the differences in the fragmentation pattern affecting the ionization current, the relative percentages are given considering only one class of compounds, particularly, the fatty acids. Other species, such as cholesterol, have been identified but not quantified as relative percentages. The most abundant fatty acids, in order of relative abundance, were identified as arachidonic acid and palmitic acid followed by eicosapentaenoic, mirystic, and eicosatrienoic acids.

\section{Supercritical $\mathrm{CO}_{2}+$ Ethanol as Co-solvent}

After the first $\mathrm{sc}-\mathrm{CO}_{2}$ extraction was run and the extract was collected, a second extraction was carried out on the previously extracted powder, keeping all the physicochemical parameters of the extraction constant but in the presence of ethanol as co-solvent in a $10 \%$ with respect to the biomass weight, as a supercritical $\mathrm{CO}_{2}$ polarity modifier.

Each point in Figure 1B corresponds to the extract weight after the solvent evaporation by a rotary evaporator $\left(37^{\circ} \mathrm{C}\right)$. The plateau was reached in this case again after 750 liters of $\mathrm{CO}_{2}$ gas have been consumed, and the extraction trial was stopped. The inset in Figure 1B shows the obtained extracts, corresponding to the first five cycles. The deep orange/red color decreased in the intensity cycle after the cycle, confirming that the biomass was exhausted in its extractable content. The final yield corresponded to $0.18 \pm 0.01 \%$ by dry weight of the starting biomass. 

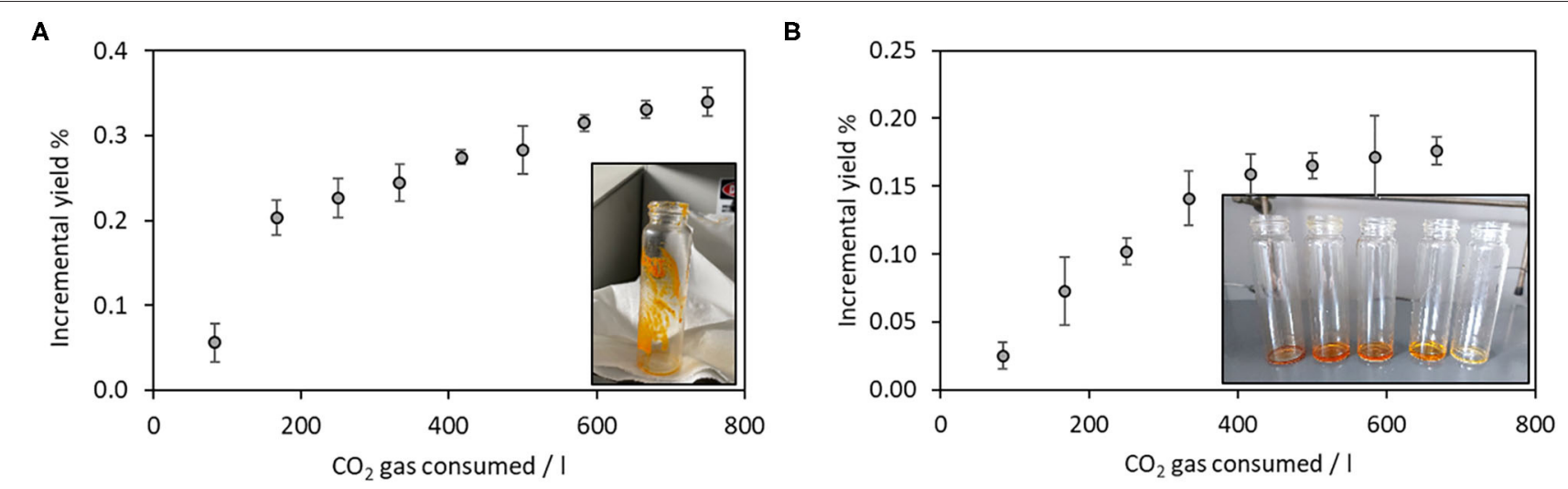

FIGURE 1 | Kinetics of supercritical fluid extraction using (A) pure $\mathrm{CO}_{2}$; (B) using ethanol as co-solvent. Insets show the visual aspect of obtained extracts. Number of replicates $=3$.

TABLE 1 | Gas chromatography-mass spectrometry (GC-MS) peaks attribution and fatty acids relative abundances.

\begin{tabular}{lllll}
\hline Peak & $\begin{array}{l}\text { Retention } \\
\text { time }\end{array}$ & \% Area & Compound & Acronym \\
\hline 1 & 14.6 & 10.0 & Myristic acid & $14: 0$ \\
2 & 18.13 & 2.2 & $\begin{array}{l}\text { Palmitoleic } \\
\text { acid }\end{array}$ & $16: 1(9 \mathrm{c})$ \\
3 & 18.57 & 24.2 & Palmitic acid & $16: 0$ \\
4 & 20.99 & 7.4 & Stearic acid & $18: 0$ \\
5 & 21.93 & 31.2 & Arachidonic & $20: 4$ \\
& & & acid $(\omega 6)$ & $(5 \mathrm{c}, 8 \mathrm{c}, 11 \mathrm{c}, 14 \mathrm{c})$ \\
6 & 21.97 & 13.9 & Eicosapentaenoic & $20: 5$ \\
& & & $\begin{array}{l}\text { acid }(\omega 3) \\
\text { Eicosatrienoic }\end{array}$ & $20: 3(11 \mathrm{c}, 14 \mathrm{c}, 17 \mathrm{c})$ \\
7 & 22.05 & 11.1 & acid $(\omega 9)$ & \\
& & & Cholesterol & - \\
8 & 27.22 & - & SFA & \\
& & 41.6 & PUFA & \\
& & 56.2 & & \\
& & & &
\end{tabular}

SFA, saturated fatty acids; PUFA, polyunsaturated fatty acids.

\section{Carotenoids Analysis}

The carotenoids identification in the sc- $\mathrm{CO}_{2}$ and $\mathrm{sc}-\mathrm{CO}_{2} \mathrm{EtOH}$ extracts was performed by liquid chromatography coupled to mass spectrometry (LC-MS).

Figure 3 displays the overlap of chromatograms recorded at $445 \mathrm{~nm}$ obtained for the sc- $\mathrm{CO}_{2}$ and sc- $\mathrm{CO}_{2} \mathrm{EtOH}$ extracts. From mass spectrometry results, it was possible to confirm the presence of astaxanthin, whose peak at a retention time of $2.5 \mathrm{~min}$, was characterized by the main signal at $m / z=597.40$, corresponding to $[\mathrm{M}+\mathrm{H}]^{+}$molecular species and a second peak at $\mathrm{m} / z=$ 579.40 , corresponding to $\left[\mathrm{M}-\mathrm{H}_{2} \mathrm{O}+\mathrm{H}\right]^{+}$species $\left(\mathrm{MW}_{\text {astaxanthin }}\right.$ $\left.=596.84 \mathrm{~g} \mathrm{~mol}^{-1}\right)(22,23)$. The presence of $\beta$-carotene was confirmed by the same strategy, and the peak at $\mathrm{t}_{\mathrm{r}}=25.3$ min was characterized by the main signal at $m / z=536.32$, corresponding to $[\mathrm{M}]^{+\bullet}$, while the secondary signal at $m / z=569.04$ corresponds to the coordination of methanol molecule $\left(\mathrm{MW}_{\beta \text {-carotene }}=\right.$ $\left.536.87 \mathrm{~g} \mathrm{~mol}^{-1}\right)$. The results are in agreement with the literature data $(21,24-26)$. By comparison with the authentic standards retention times $\left(t_{r}\right)$, both the sc- $\mathrm{CO}_{2}$ and $\mathrm{sc}-\mathrm{CO}_{2} \mathrm{EtOH}$ extracts are found to contain astaxanthin $\left(\mathrm{t}_{\mathrm{r}}=2.5 \mathrm{~min}\right)$ and $\beta$-carotene $\left(\mathrm{t}_{\mathrm{r}}=25.3 \mathrm{~min}\right)$.

Lutein was excluded in the assignments of peaks in the samples chromatograms, as confirmed by the co-injection with lutein authentic standard. The main peak, eluting at $21.2 \mathrm{~min}$ was then attributed to echinenone. The presence of echinenone was confirmed by UPLC-TUV-MS. The corresponding peak was characterized by the main signal at $m / z=551.44$, corresponding to $[\mathrm{M}+\mathrm{H}]^{+}$echinenone molecular species $\left(\mathrm{MW}_{\text {echinenone }}=\right.$ $\left.550.85 \mathrm{~g} \mathrm{~mol}^{-1}\right)$. The results are in agreement with the literature data $(22,27)$.

Carotenoids quantification was carried out by UPLC. Six dilutions of the starting standards of astaxanthin, lutein, and $\beta$-carotene solutions (in chloroform:acetonitrile $=1: 10$ ) were prepared in the range of $0.6-70,0.9-30$, and $0.9-116 \mu \mathrm{g} \mathrm{ml}^{-1}$ for astaxanthin, lutein, and $\beta$-carotene, respectively. Standard solutions were injected three times in the UPLC system and monitored at $445 \mathrm{~nm}$. All compounds were eluted as single sharp peaks at a retention time of $2.5 \mathrm{~min}$ for astaxanthin, $20.1 \mathrm{~min}$ for lutein, and $25.3 \mathrm{~min}$ for $\beta$-carotene. In the operative concentration range, the trend was linear, with no saturation effects that could bend the linearity. No standards were available for echinenone. Its quantification has been performed using the calibration line of astaxanthin, being the molar extinction coefficients of astaxanthin and echinenone similar $\left[125 \cdot 10^{3} 1\right.$ and $\left.119 \cdot 10^{3} 1 \mathrm{~mol}^{-1} \mathrm{~cm}^{-1}(28,29)\right]$. The area under each peak was quantified by Empower 3 instrumental software and plotted vs. the concentration. The best fit of experimental data in the plot "Peak area vs. [carotenoid]" was, as expected, a straightline, represented by the following mathematical equations: $y$ $=\left(1.97 \cdot 10^{8} \pm 2 \cdot 10^{6}\right) \mathrm{x}+\left(-1.2 \cdot 10^{5} \pm 5 \cdot 10^{4}\right)$ for astaxanthin standard solutions $\left(\mathrm{LOD}=0.9 \mu \mathrm{g} \mathrm{ml}^{-1}, \mathrm{LOQ}=2.7 \mu \mathrm{g} \mathrm{ml}^{-1}\right.$ ), $y=\left(6.81 \cdot 10^{7} \pm 8 \cdot 10^{5}\right) x+\left(5 \cdot 10^{5} \pm 2 \cdot 10^{5}\right)$ for lutein standard solutions $\left(\mathrm{LOD}=1.1 \mu \mathrm{g} \mathrm{ml}^{-1}\right.$, LOQ $=3.3 \mu \mathrm{g} \mathrm{ml}^{-1}$ ) and $\mathrm{y}=\left(6.76 \cdot 10^{7} \pm 5 \cdot 10^{5}\right) \mathrm{x}+\left(5 \cdot 10^{5} \pm 1 \cdot 10^{5}\right)$ for $\beta$-carotene standard solutions $\left(\mathrm{LOD}=1.8 \mu \mathrm{g} \mathrm{ml}^{-1}\right.$, LOQ $=5.6 \mu \mathrm{g} \mathrm{ml}^{-1}$ ). Linearity was assessed through the evaluation of the coefficient of 


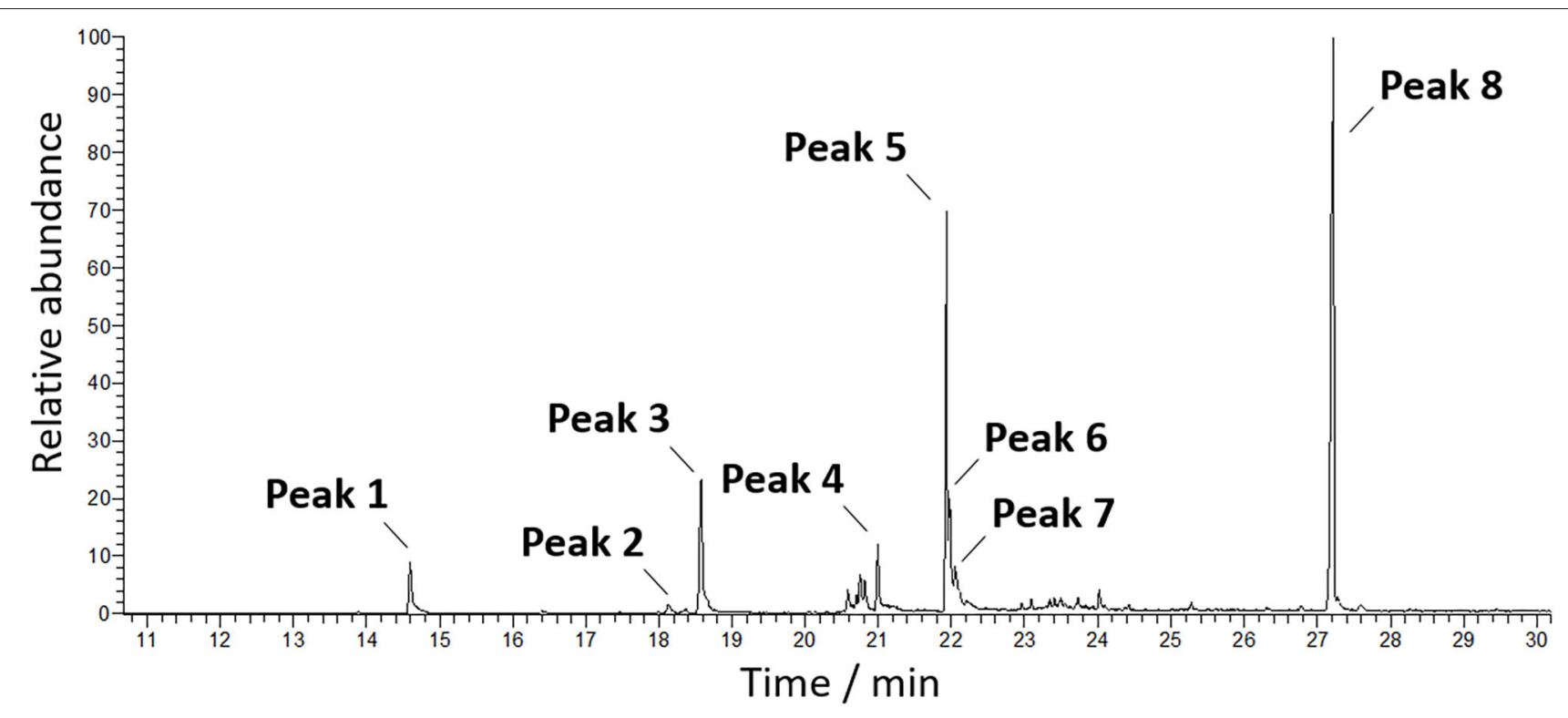

FIGURE 2 | Total ion current-mass spectrometry (TIC-MS) chromatograms of the sc- $\mathrm{CO}_{2}$ extract.

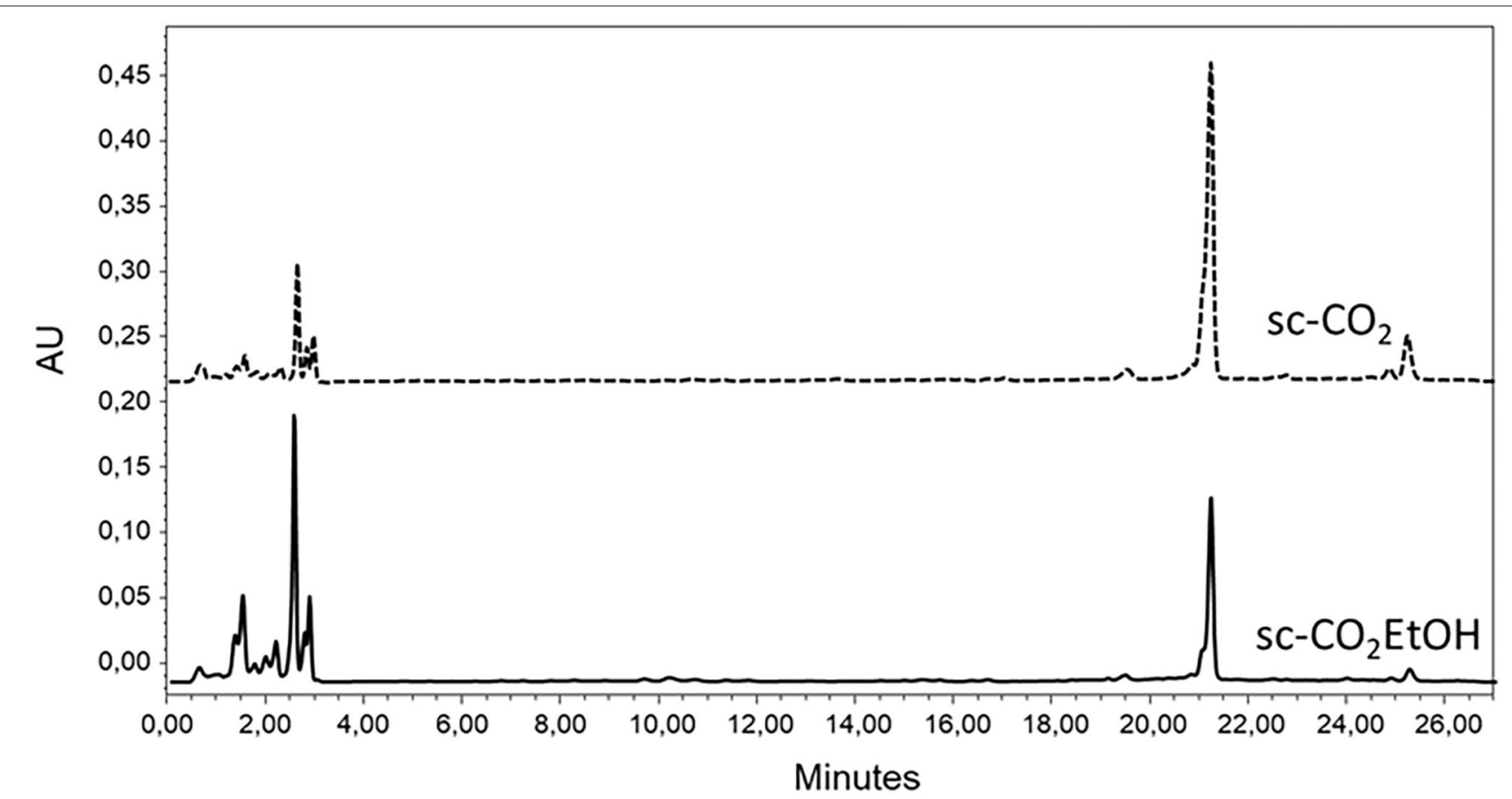

FIGURE 3 | Ultrahigh-performance liquid chromatograms of sc- $\mathrm{CO}_{2}$ and sc- $\mathrm{CO}_{2} \mathrm{EtOH}$ extracts (445 nm).

determination, which should be $>0.998$; in all cases, it was equal to 0.999 .

Based on these results, the calculated equations of the regression line were then employed to determine the carotenoids concentration in the $\mathrm{sc}-\mathrm{CO}_{2}$ and $\mathrm{sc}-\mathrm{CO}_{2} \mathrm{EtOH}$ extracts. Results are displayed in Table 2.
From the results displayed in Table 2, the amount of astaxanthin is shown to 10 -fold increase when ethanol was employed as co-solvent during the supercritical $\mathrm{CO}_{2}$ extraction. A slight increase (about 2-fold) was recorded also for echinenone and $\beta$-carotene. 
TABLE 2 | Carotenoids concentrations in the extracts and in the starting dry biomass. Number of replicates $=3$.

\begin{tabular}{|c|c|c|c|c|}
\hline & Carotenoid & $\mathrm{mg}_{\text {carotenoid }} / \mathrm{g}_{\text {extract }}$ & $\mathrm{mg}_{\text {carotenoid }} / \mathbf{k g}$ dry biomass & Relative percentages (\%) \\
\hline \multirow[t]{3}{*}{$\mathrm{sc}-\mathrm{CO}_{2}$} & $\beta$-carotene & $0.18 \pm 0.03$ & $0.67 \pm 0.06$ & $11 \pm 1$ \\
\hline & Echinenone & $1.26 \pm 0.05$ & $4.6 \pm 0.4$ & $75 \pm 6$ \\
\hline & Astaxanthin & $0.25 \pm 0.01$ & $0.92 \pm 0.09$ & $15 \pm 1$ \\
\hline \multirow[t]{3}{*}{$\mathrm{sc}-\mathrm{CO}_{2} \mathrm{EtOH}$} & $\beta$-carotene & $0.35 \pm 0.05$ & $2.0 \pm 0.5$ & $7 \pm 1$ \\
\hline & Echinenone & $1.89 \pm 0.08$ & $11 \pm 2$ & $39 \pm 4$ \\
\hline & Astaxanthin & $2.64 \pm 0.09$ & $15 \pm 1$ & $54 \pm 7$ \\
\hline
\end{tabular}

\section{PHNQ Extraction}

\section{Solvent-Based Extraction}

Attempts of extraction of PHNQ in supercritical conditions were carried out changing different physicochemical parameters and the co-solvent nature and percentages but none of the trials were found successful. For this reason, a modification of solvent-based extraction procedures was optimized. The starting carbonate matrix decomposition by aqueous formic acid is necessary to make the successive PHNQ extraction easier. Direct treatment of the powder of sea urchins with ethyl acetate is indeed unable to yield PHNQ. After formic acid decomposition and ethyl acetate counter extraction, the organic phase was characterized by a pink-orange color (as shown in the upper phase in Figure 4). Multiple washing steps with water were necessary to remove salts (calcium and magnesium formiate) due to the slight solubility of water in ethyl acetate that could affect the final PHNQ yield. The final yield was $0.07 \pm 0.01 \%$ (on dry biomass). The extraction was run five times to get a standard deviation.

\section{Total Phenolic Content}

Total phenolic content was determined using the Folin Ciocalteu colorimetric assay. The extract displayed a high TPC value, expressed as gallic acid equivalents per gram of extract, corresponding to $441 \pm 24 \mathrm{mg} \mathrm{GAE} / \mathrm{g}$ extract.

\section{PHNQ Extract Characterization}

After solvent removal by the evaporation under vacuum, the organic phase was injected in UPLC-PDA-ESI-HRMS to identify the PHNQ present in the extract. Figure 5 displays the results.

By $m / z$ results, displayed in Figures 5B,C, Peak 1 and Peak 2 have been clearly attributed to Spinochrome $\mathrm{B}(\mathrm{m} / \mathrm{z}=$ $221.0086 \mathrm{Da}$; calculated mass $=221.0086 \mathrm{Da}$ for $\left.\mathrm{C}_{10} \mathrm{H}_{5} \mathrm{O}_{6}\right)$ and Spinochrome A $(m / z=263.0197 \mathrm{Da}$; calculated mass $=263.0192$ $\mathrm{Da}$ for $\left.\mathrm{C}_{12} \mathrm{H}_{7} \mathrm{O}_{7}\right)(12,16)$.

\section{PHNQ Antioxidant Activity}

The radical scavenging activity of the PHNQ extract was determined by the ABTS assay and then compared to the watersoluble analog of vitamin E, Trolox ${ }^{\circledR}$, and results are expressed as Trolox ${ }^{\circledR}$ equivalents. The radical scavenging activity of PHNQ extract was determined by the ABTS radical cation decolorization assay, as shown in Figure 6.

The $\mathrm{EC}_{50}$ values, calculated for both PHNQ extract and Trolox ${ }^{\circledR}$, confirming the high antioxidant activity of the extract from the sea urchins, correspond to $0.004 \pm 0.001$ and $0.0035 \pm$

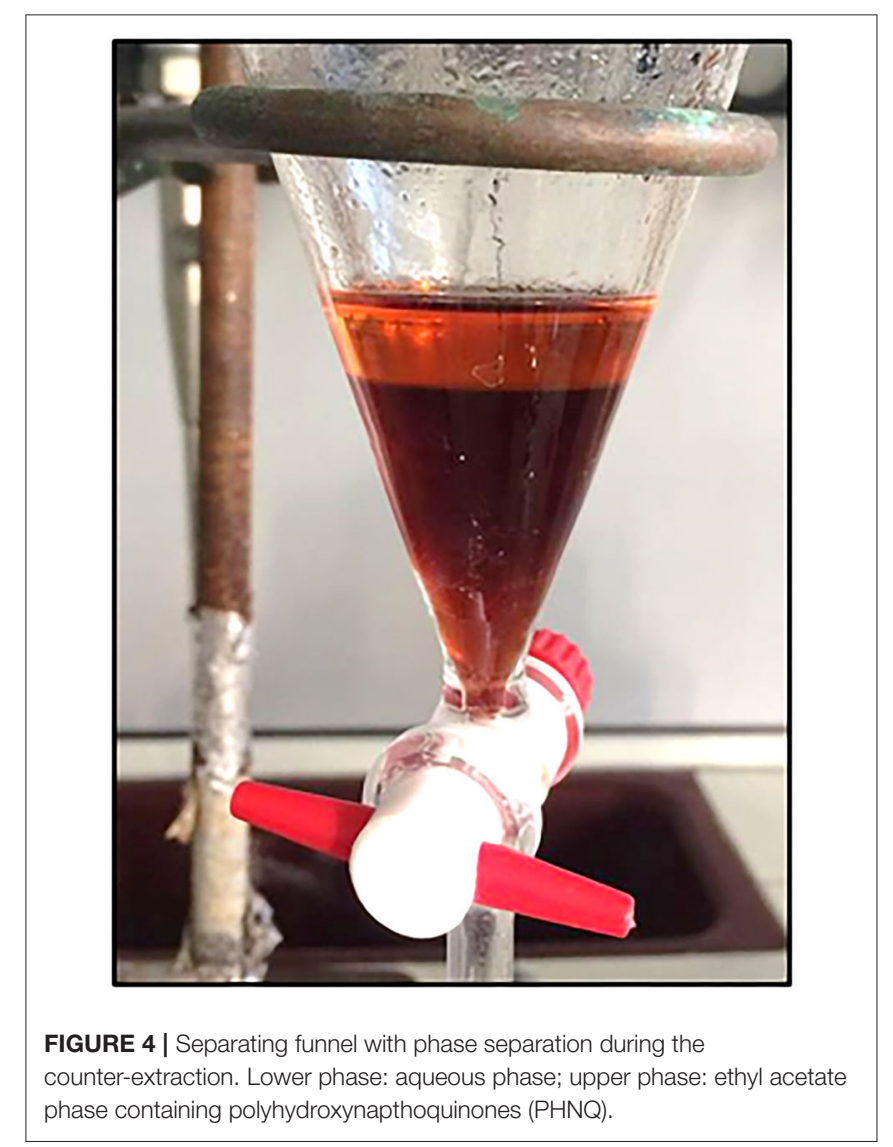

$0.0005 \mathrm{mg} \mathrm{ml}^{-1}$, respectively. In terms of Trolox ${ }^{\circledR}$ equivalents, this value amounts to $875 \pm 252 \mathrm{mg}$ Trolox $\mathrm{g}_{\text {extract}}^{-1}$.

\section{DISCUSSION}

\section{Lipids}

The use of supercritical $\mathrm{CO}_{2}$ was found mandatory when targeting lipids from the waste of sea urchins. Probably due to matrix effects, mass transfer of compounds of interests was hindered when "conventional" organic solvents were employed (such as hexane, dichloromethane, and chloroform).

Both the initial extractions, carried out by using supercritical $\mathrm{CO}_{2}$ in the presence and absence of co-solvent, are characterized by similarities in their kinetics. Indeed, according to the literature, extraction curves can be divided into three 


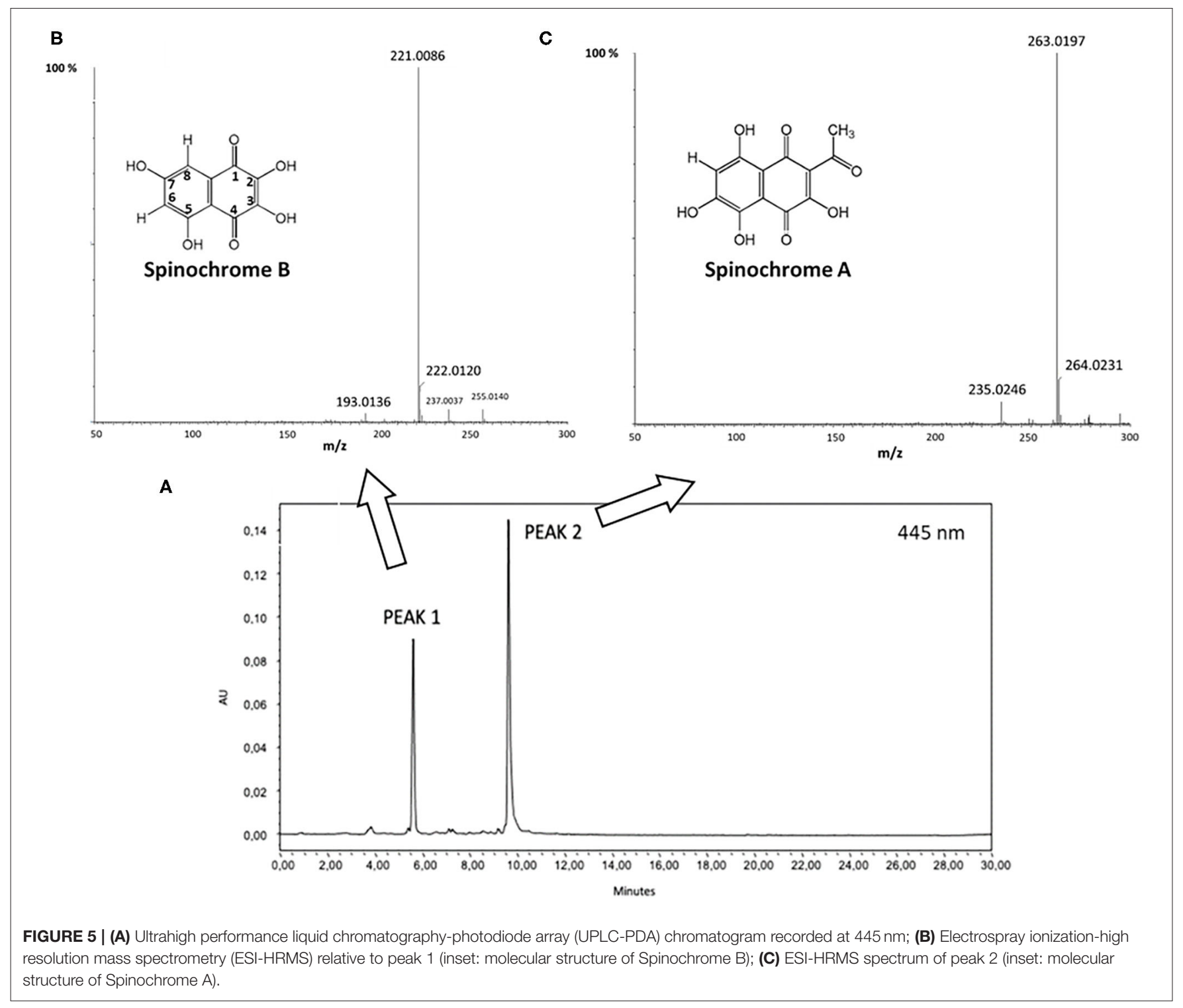

kinetic stages, each one controlled by different mass transfer mechanisms: (1) the constant extraction rate (CER), where the convection is the dominant mass transfer mechanism; (2) the falling extraction rate (FER), where the diffusion mechanism starts, operating combined with convection; (3) the diffusioncontrolled period, where the mass transfer occurs mainly by diffusion in the bed and inside the solid substrate particles (30). Figures 1A,B clearly displays these three steps, corresponding to a starting high rate of extraction, followed by the plateau, assessing and confirming the consecutive kinetics of extraction from the biomass. Different from the extraction performed in the presence of ethanol as co-solvent, when $\mathrm{CO}_{2}$ was present alone, the first stage of the extraction was steep (up to $200 \mathrm{~L}$ of employed $\mathrm{CO}_{2}$ ), confirming the prompt solubilization in the supercritical fluid of the extractable compounds. The steepness of the first stage of the extraction was, on the other hand, lower in the presence of ethanol as co-solvent, confirming a more hindered mass transfer of the extractable compounds in these physicochemical conditions.

The sc- $\mathrm{CO}_{2}$ extract $(168 \pm 10 \mathrm{mg}$ ), obtained from the pristine waste of sea urchin lyophilized powder at $60^{\circ} \mathrm{C}$ and 200 bar, containing about $41.6 \%$ of saturated fatty acids (SFA) and $56.2 \%$ of polyunsaturated fatty acids (PUFA). The ratio SFA/PUFA is in favor of the polyunsaturated fatty acids. Myristic, palmitic, and stearic acids were the main SFA (Table 1). The composition of long-chain polyunsaturated fatty acids (LC-PUFAs) was characterized by three major components, arachidonic acid in the largest amount, eicosapentaenoic acid, and eicosatrienoic acid with comparable relative concentrations. $\omega 6$ PUFA was indeed the main component, compared to $\omega 3$ and $\omega 9$. These LC-PUFAs possess important properties since they act as the precursors of eicosanoids, a family of bioactive lipid mediators that regulate a wide variety of physiological as well as pathological responses and often exhibit potent inflammatory properties (29). 


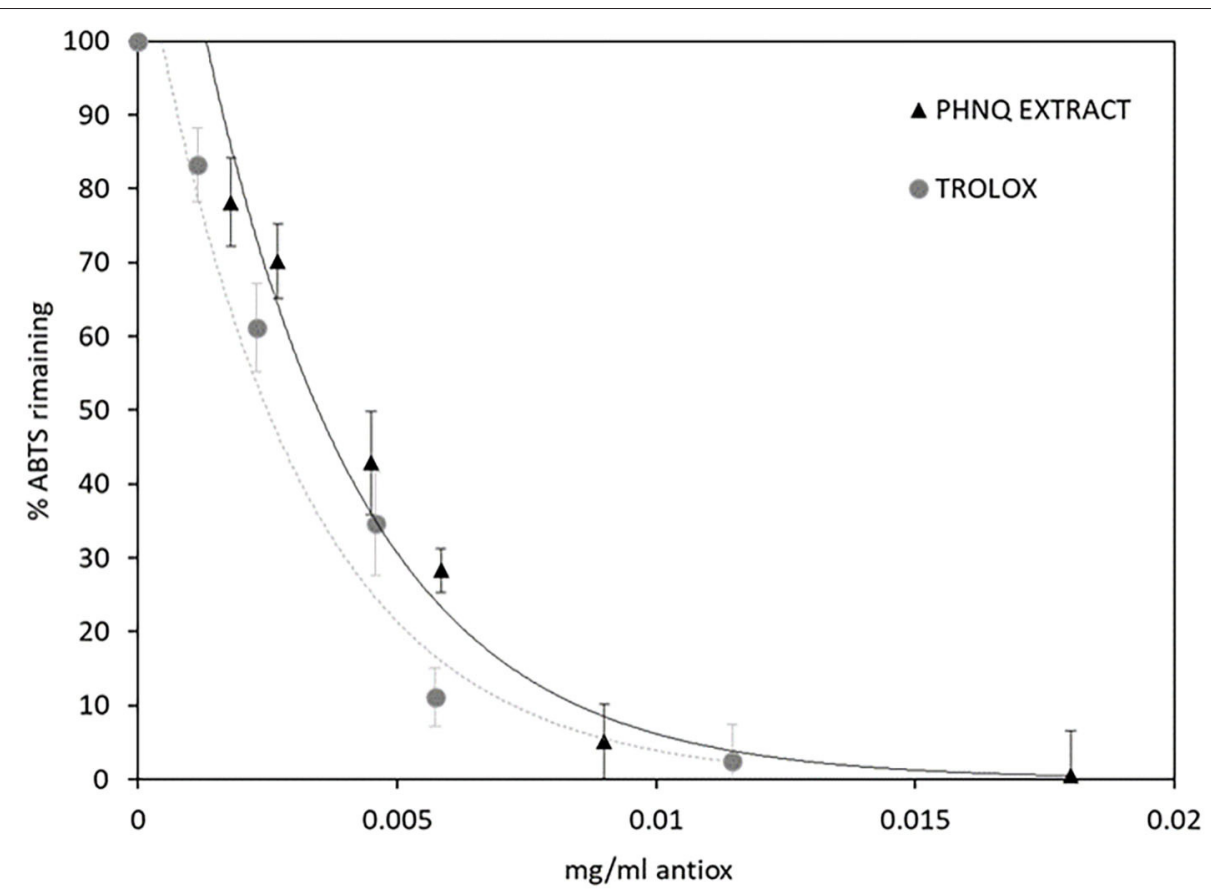

FIGURE 6 | ABTS \% remaining after the incubation period in the presence of different concentrations of PHNQ extract and Trolox ${ }^{\circledR}$, as reference. Number of replicates $=3$.

The presence of cholesterol in the pure $\mathrm{sc}-\mathrm{CO}_{2}$ extract is not surprising, being the main sterol among the constituents of the gonads of the sea urchins $(10,31)$.

Together with fatty acids and sterols, supercritical $\mathrm{CO}_{2}$ alone was also able to yield carotenoids.

In particular, as shown in Table 2, the most abundant carotenoid in the extract, as detected by UPLC, was echinenone (with a relative percentage of $75 \%$ ). In particular, echinenone has been already studied in the literature as the major carotenoid found in the gonads of sea urchins (up to $50-60 \%$ of the total pigments) (32). This suggested that it may have a role in their reproduction $(33,34)$. In terms of relative concentration in the extract, echinenone was followed by astaxanthin (15\%) and then $\beta$-carotene (11\%). When the extraction was run on the previously extracted biomass, but in the presence of ethanol as co-solvent, acting as polarity modifier, $81 \pm 5 \mathrm{mg}$ of the extract have been collected.

In this extract, the relative percentages of detected carotenoids were deeply affected, now yielding astaxanthin as the major carotenoid in the sc- $\mathrm{CO}_{2} \mathrm{EtOH}$ extract (relative percentage of $54 \%$ ). Bearing hydroxyl groups on the terminal ring systems of the carotenoid-based structure, astaxanthin is characterized by an enhanced polarity and hence is more easily extractable in the presence of a co-solvent. The amount of $\beta$-carotene slightly decreased and echinenone halves its presence down to $39 \%$.

Looking at the concentrations of each carotenoid in the starting dry biomass (fourth column in Table 2), even if the values seem low in terms of carotenoids content (in the order of magnitude of mg per kilogram of dry biomass), these are in agreement with the literature data quantifying the amount of carotenoids from different sources such as feed additives for fishes and laying hens $(35,36)$. These additives are employed in this field because carotenoids, such as astaxanthin, are demonstrated to promote growth rates during the early startfeeding period. Subsequently, positive effects of carotenoids as supplements, even in the order of $\mathrm{mg}$ per $\mathrm{kg}$ of diet, to commercial start-feeding diets, on the growth of some fish species, have been reported.

\section{Polyhydroxynapthoquinones}

As a further step, after carotenoids extraction, identification, and quantification, the focus was shifted to the PHNQ class of compounds. Due to their polyhydroxylated quinonoid nature, their extractability in supercritical conditions is hindered, even in the presence of different co-solvents (ethanol, methanol, water, etc.). After different experimental trials, a solvent-based extraction was assessed as the optimal strategy, performed with modifications with respect to some literature methods (16). The main constituents of the wastes of sea urchins are calcium and magnesium carbonate, accounting for more than $90 \%$ of their weight, PHNQs are hence compartmented inside the inorganic matrix (37). By ICP-OES analyses, the molar ratio between $\mathrm{Ca}$ and $\mathrm{Mg}$ was found to be 16:1. When formic acid decomposes the carbonate-based powder of sea urchins, the following reaction occurs, yielding calcium 
formiate (an analog reaction occurs for magnesium, producing magnesium formiate):

$$
\mathrm{Ca}^{2+}+\mathrm{CO}_{3}^{2-}+2 \mathrm{HCOOH} \rightarrow \mathrm{Ca}^{2+}+2 \mathrm{HCOO}^{-}+\mathrm{CO}_{2}+\mathrm{H}_{2} \mathrm{O}(2)
$$

In addition, $\mathrm{Ca}$ and $\mathrm{Mg}$ formiate, highly soluble in water, can partially contaminate the ethyl acetate phase, affecting the PHNQ yield. This is due to the partial solubility of water in ethyl acetate $\left(3.3 \%\right.$ at $\left.20^{\circ} \mathrm{C}\right)(38)$. For this reason, many washing steps by water aliquots were found necessary to remove salts from the ethyl acetate phase containing PHNQ. The specific conductivity of each successive aliquot of water was measured until its value was comparable to the pristine deionized water. The final yield, equal to $0.07 \pm 0.01 \%$ by weight of the starting biomass, was hence not affected by the presence of residual salts.

The presence of phenolic structures in the obtained extract was confirmed by Folin-Ciocateu assay. In the absence of authentic standards, not commercially available, the determination of the TPC is a good measure of the presence of the targeted compounds. In terms of gallic acid equivalents, the TPC (441 $\pm 24 \mathrm{mg} \mathrm{GAE} / \mathrm{g}$ extract $)$ was surprisingly high, confirming the successful extraction of PHNQ and salts removal.

The identification of Spinochrome B and Spinochrome A by UPLC-HRMS was in agreement with the literature data, since the species under study, Paracentrotus lividus, has been already demonstrated to contain these pigments $(14,39)$.

Molar extinction coefficients of spinochrome A $(\varepsilon=3,3111$ $\mathrm{mol}^{-1} \mathrm{~cm}^{-1}$ at $\left.520 \mathrm{~nm}\right)$ and spinochrome B $\left(\varepsilon=4,898 \mathrm{~mol}^{-1}\right.$ $\mathrm{cm}^{-1}$ at $480 \mathrm{~nm}$ ) have been already determined in the literature and quantification of the content of each spinochrome $\mathrm{A}$ and $\mathrm{B}$ were performed by using Lawsone as standard, considering the relative ratio between its molar extinction coefficient $(\varepsilon=$ $1,2000 \mathrm{~L} \mathrm{~mol}^{-1} \mathrm{~cm}^{-1}$ at $462 \mathrm{~nm}$ ) and the PHNQ ones $(40,41)$. Lawsone, 2-hydroxy-1,4-naphthoquinone, is indeed structurally similar to $\mathrm{PHNQ}$, bearing a monohydroxylated naphtoquinone skeleton. By this calculation, the extract was demonstrated to contain $19 \%$ by weight of Spinochrome B and $21 \%$ by weight of Spinochrome A, accounting for $40 \%$ of the weight of the extract. This value is in agreement with the TPC content previously determined.

The antioxidant properties of PHNQ pigments have been investigated in several different models. Interestingly, it was shown that the radical scavenging activity of pigments depends on the number and positions of the hydroxyl groups. In detail, the hydroxyl groups in the C-2, C-3, and C-7 positions (as shown numeration in Figure 5) play a beneficial role in the radical scavenging capacity, while the hydroxyl groups at C5 and C-8 positions hinder hydrogen atom donation and adversely influence the free radical scavenging capacity (14). Spinochrome B displays all the $\mathrm{OH}$ beneficial groups in 2, 3, and 7 positions, Spinochrome A carries only one beneficial $\mathrm{OH}$ group in position 3 of the quinonoid ring. These features, together with their relative quantification in the extract, account for the high antioxidant activity measured by the ABTS radical cation decolorization assay. The $\mathrm{EC}_{50}$ value measured for the PHNQ extract, equal to $0.004 \pm 0.001 \mathrm{mg} \mathrm{ml}^{-1}$, is comparable to the $\mathrm{EC}_{50}$ of Trolox ${ }^{\circledR}\left(0.0035 \pm 0.0005 \mathrm{mg} \mathrm{ml}^{-1}\right)$ and with results from Utkina et al. (42). Other studies in the literature found higher $\mathrm{EC}_{50}$ values, due to differences in the content of the pigment, depending on the investigated species of the sea urchin (43).

\section{CONCLUSION}

This study validates the use of successive extraction strategies of added-value compounds, targeting specific chemical species, characterized by different polarities, aiming at valorizing the wastes of sea urchin. Sea urchin's waste whole content was indeed investigated for the first time in its lipidic species, belonging to the fatty acids and carotenoids classes, which were successfully extracted by means of a green technique, supercritical $\mathrm{CO}_{2}$ in the absence, and presence of a cosolvent like ethanol. PUFA and carotenoids such as echinenone, astaxanthin, and $\beta$-carotene were identified and quantified in the extracts. Their presence is possibly attributable to the residues of gonads and other soft tissue remains (e.g., digestive tract) after sea urchins consumption as a food delicacy. The defatted biomass, comprising the tests and spines, was then reextracted to yield polyhydroxy-1,4-naphtoquinones, whose high interest is related to the multiple antioxidants, biological, and pharmacological activities.

Overall, the antioxidant activities measured for the PHNQ were highly remarkable, pointing to the use of this kind of waste for multiple applications when the radical scavenging activities are key features.

For example, they could be used as an additive in the further development of sea urchin collagen-based biomaterials to produce bioactive devices for regenerative medicine able to simultaneously provide both structural/filler (collagen) as well anti-oxidant and anti-inflammatory (PHNQ) properties.

The presence of added-value lipid compounds, such as PUFA and carotenoids, together with the more polar hydroxylated quinonoid-like compounds, Spinochrome B and Spinochrome A, enriching the carbonate-based matrix, opens the way to potential reuses of the waste toward other applications. The latter could be related, for example, to the development of feed additives for animals specifically requiring a high amount of calcium carbonates, such as laying hens or sea urchins themselves. Particularly, the development of optimal growthpromoting feed for sea urchin aquaculture (echinoculture) will hopefully promote this practice and reduce the impacts on natural stocks.

\section{DATA AVAILABILITY STATEMENT}

The raw data supporting the conclusions of this article will be made available by the authors, without undue reservation.

\section{AUTHOR CONTRIBUTIONS}

SM was responsible for study design, supervised experiments, and wrote and revised the manuscript. GM performed the experiments and wrote part of the manuscript. MS refined and 
revised the manuscript. LV supervised the project, refined, and revised the manuscript. All authors contributed to the article and approved the submitted version.

\section{FUNDING}

The present research was financed by Cariplo Foundation (CIRCULAr project-2019-2169) and MIUR-PRIN (BRITEs project-2017FNZPNN).

\section{REFERENCES}

1. United Nations. Department of Economic and Social Affairs Sustainable Development. Available online at: https://sdgs.un.org/goals (accessed June 14, 2021).

2. Zilia F, Bacenetti J, Sugni M, Matarazzo A, Orsi L. From waste to product: circular economy applications from sea Urchin. Sustainability. (2021) 13:5427. doi: 10.3390/su13105427

3. Stefánsson G, Kristinsson H, Ziemer N, Hannon C, James P. Markets for Sea Urchins: A Review of Global Supply and Markets. Skýrsla Matís (2017) 45. p.

4. Grisolía JM, López F, Ortúzar J de D. Sea urchin: from plague to market opportunity. Food Qual Prefer. (2012) 25:4656. doi: 10.1016/j.foodqual.2012.01.004

5. Di Benedetto C, Barbaglio A, Martinello T, Alongi V, Fassini D, Cullorà E, et al. Production, characterization and biocompatibility of marine collagen matrices from an alternative and sustainable source: the sea urchin Paracentrotus lividus. Mar Drugs. (2014) 12:4912-33. doi: 10.3390/md12094912

6. Ferrario C, Rusconi F, Pulaj A, Macchi R, Landini P, Paroni M, et al. From food waste to innovative biomaterial: sea urchin-derived collagen for applications in skin regenerative medicine. Mar Drugs. (2020) 18:414. doi: 10.3390/md18080414

7. Ferrario C, Leggio L, Leone R, Di Benedetto C, Guidetti L, Coccè V, et al. Marine-derived collagen biomaterials from echinoderm connective tissues. Mar Environ Res. (2017) 128:46-57. doi: 10.1016/j.marenvres.2016.03.007

8. Melotti L, Martinello T, Perazzi A, Iacopetti I, Ferrario C, Sugni M, et al. A prototype skin substitute, made of recycled marine collagen, improves the skin regeneration of sheep. Animals. (2021) 11:1-20. doi: 10.3390/ani11051219

9. Carroll AR, Copp BR, Davis RA, Keyzers RA, Prinsep MR. Marine natural products. Nat Prod Rep. (2020) 37:175-223. doi: 10.1039/C9NP00069K

10. Shikov AN, Laakso I, Pozharitskaya ON, nen-Laakso TS, Krishtopina AS, Makarova $\mathrm{MN}$, et al. Chemical profiling and bioactivity of body wall lipids from strongylocentrotus droebachiensis. Mar Drugs. (2017) 15:111. doi: $10.3390 / \mathrm{md} 15120365$

11. Brasseur L, Hennebert E, Fievez L, Caulier G, Bureau F, Tafforeau L, et al. The roles of spinochromes in four shallow water tropical sea urchins and their potential as bioactive pharmacological agents. Mar Drugs. (2017) 15:179. doi: $10.3390 / \mathrm{md} 15060179$

12. Brasseur L, Caulier G, Flammang P, Eeckhaut I, Demeyer M, Decroo $\mathrm{C}$, et al. Identification and quantification of spinochromes in body compartments of Echinometra mathaei's coloured types. R Soc Open Sci. (2018) 5:171213. doi: $10.1098 /$ rsos. 171213

13. Vasileva E, Mishchenko NP. Diversity of polyhydroxynaphtoquinone pigments in north pacific sea urchins. Chem Biodivers. (2017) 14:e1700182. doi: $10.1002 / \mathrm{cbdv} .201700182$

14. Shikov AN, Pozharitskaya ON, Krishtopina AS, Makarov VG. Naphthoquinone pigments from sea urchins: chemistry and pharmacology. Phytochem Rev. (2018) 17:509-34. doi: 10.1007/s11101-018-9547-3

15. Rubilar T, Barbieri ES, Gazquez A, Avaro M. Sea urchin pigments: echinochrome a and its potential implication in the cytokine storm syndrome. Mar Drugs. (2021) 19:267. doi: 10.3390/md19050267

16. Powell C, Hughes AD, Kelly MS, Conner S, Mc Dougall GJ. Extraction and identification of antioxidant polyhydroxynaphthoquinone pigments from the

\section{ACKNOWLEDGMENTS}

Wastes of sea urchins were kindly donated by Acqua e Sale Il, Il Grissino, Lo stuzzichino di Mare and Charmant restaurants in Milan. Mass spectrometry analyses were performed at the MS facility of the Unitech COSPECT at the University of Milan (Italy). The authors thank Dr. Paolo Spontoni and Dr. Marco Schiavoni for GC-MS analyses and Dr. Americo Costantino for the ICP-OES facilities. sea urchin, Psammechinus miliaris. LWT - Food Sci Technol. (2014) 59:45560. doi: 10.1016/j.lwt.2014.05.016

17. Slinkard K, Singleton VL. Total phenol analysis: automation ans comparison with manual methods. Am J Enol Vitic. (1977) 28:49-55.

18. Loganayaki N, Siddhuraju P, Manian S. Antioxidant activity and free radical scavenging capacity of phenolic extracts from Helicteres isora L. and Ceiba pentandra L. J Food Sci Technol. (2013) 50:687-95. doi: 10.1007/s13197-011-0389-x

19. Tripodi F, Lombardi L, Guzzetti L, Panzeri D, Milanesi R, Leri M, et al. Protective effect of Vigna unguiculata extract against aging and neurodegeneration. Aging. (2020) 12:19785-803. doi: 10.18632/aging.104069

20. Ermer J. Validation in pharmaceutical analysis. Part I: an integrated approach. J Pharm Biomed Anal. (2001) 24:755-67. doi: 10.1016/s0731-7085(00)00530-6

21. Marzorati S, Schievano A, Idà A, Verotta L. Carotenoids, chlorophylls and phycocyanin from Spirulina: supercritical $\mathrm{CO}_{2}$ and water extraction methods for added value products cascade. Green Chem. (2020) 22:187-96. doi: $10.1039 / \mathrm{c} 9 \mathrm{gc} 03292 \mathrm{~d}$

22. Miao F, Lu D, Li Y, Zeng M. Characterization of astaxanthin esters in Haematococcus pluvialis by liquid chromatography-atmospheric pressure chemical ionization mass spectrometry. Anal Biochem. (2006) 352:17681. doi: 10.1016/j.ab.2006.03.006

23. Jonathan Posner Bradley S. Peterson JAR. Atmospheric pressure chemical ionization tandem mass spectrometry of carotenoids. Int J Mass Spectrom. (2012) 312:163-72. doi: 10.1016/j.ijms.2011.07.030

24. Rivera SM, Christou P, Canela-Garayoa R. Identification of carotenoids using mass spectrometry. Mass Spectrom Rev. (2014) 33:353-72. doi: 10.1002/mas. 21390

25. Li H, Tyndale ST, Heath DD, Letcher RJ. Determination of carotenoids and alltrans-retinol in fish eggs by liquid chromatography-electrospray ionizationtandem mass spectrometry. J Chromatogr B Anal Technol Biomed Life Sci. (2005) 816:49-56. doi: 10.1016/j.jchromb.2004.11.005

26. Chakrabarti R. Carotenoprotein from tropical brown shrimp shell waste by enzymatic process. Food Biotechnol. (2002) 16:81-90. doi: 10.1081/FBT-120004202

27. Rivera S, Vilaró F, Canela R. Determination of carotenoids by liquid chromatography/mass spectrometry: effect of several dopants. Anal Bioanal Chem. (2011) 400:1339-46. doi: 10.1007/s00216-011-4825-6

28. Davies BH. Analysis of Carotenoid Pigments in Chemistry Biochemistry of Plant Pigment. ed Goodw TW. London, New York, NY: Academic Press (1965).

29. Tomas RN, Cox ER, Steidinger KA. Pigments of the dinoflagellate peridinium balticum and its photosynthetic endosymbiont. J Phycol. (1977) 13:354-8.

30. Nasti R, Galeazzi A, Marzorati S, Zaccheria F, Ravasio N, Luisa G, et al. Valorisation of coffee roasting by - products : recovery of silverskin fat by supercritical - $\mathrm{CO}_{2}$ extraction. Waste Biomass Valoriz. (2021). doi: 10.1007/s12649-021-01435-9

31. López-Hernández J, González-Castro MJ, Piñeiro-Sotelo M. Determination of sterols in sea urchin gonads by high-performance liquid chromatography with ultraviolet detection. J Chromatogr Sci. (1999) 37:237-9. doi: 10.1093/chromsci/37.7.237

32. Symonds RC, Kelly MS, Caris-Veyrat C, Young AJ. Carotenoids in the sea urchin Paracentrotus lividus: occurrence of $9^{\prime}$-cis-echinenone as the dominant carotenoid in gonad colour determination. Comp Biochem Physiol - B Biochem Mol Biol. (2007) 148:432-44. doi: 10.1016/j.cbpb.2007.07.012 
33. Galasso C, Corinaldesi C, Sansone C. Carotenoids from marine organisms: biological functions and industrial applications. Antioxidants. (2017) 6:96. doi: 10.3390/antiox6040096

34. Tsushlma M, Kawakami M, Mine M, Matsuno T. The role of carotenoids in the development of the sea urchin pseudocentrotus depressus. Invertebr Reprod Dev. (1997) 32:149-53. doi: 10.1080/07924259.1997.9672616

35. Moreno JA, Díaz-Gómez J, Nogareda C, Angulo E, Sandmann G, PorteroOtin M, et al. The distribution of carotenoids in hens fed on biofortified maize is influenced by feed composition, absorption, resource allocation and storage. Sci Rep. (2016) 6:35346. doi: 10.1038/srep35346

36. Meyers SP. Developments in world aquaculture, feed formulations, and role of carotenoids. Pure Appl Chem. (1994) 66:106976. doi: 10.1351/pac199466051069

37. Drozdov AL, Sharmankina VV, Zemnukhova LA, Polyakova NV. Chemical composition of spines and tests of sea urchins. Biol Bull. (2017) 43:521-31. doi: 10.1134/S1062359016060078

38. Ethyl Acetate Solvent Properties. Available online at: https://macro.lsu.edu/ HowTo/solvents/ethylacetate.htm (accessed June 9, 2021).

39. Goodwin TW, Srisukh S. A study of the pigments of the sea-urchins, Echinus esculentus L. and Paracentrotus lividus Lamarck. Biochem J. (2015) 47:69-76. doi: 10.1042/bj04 70069

40. Soleimani S, Yousefzadi M, moein S, Rezadoost H, Bioki NA. Identification and antioxidant of polyhydroxylated naphthoquinone pigments from sea urchin pigments of Echinometra mathaei. Med Chem Res. (2016) 25:147683. doi: 10.1007/s00044-016-1586-y

41. Khadtare SS, Ware AP, Salunke-Gawali S, Jadkar SR, Pingale SS, PathanShubhangi HM. Dye sensitized solar cell with lawsone dye using $\mathrm{ZnO}$ photoanode: experimental and TD-DFT study. RSC Adv. (2015) 5:17647-52. doi: 10.1039/C4RA14620D

42. Utkina NK, Pokhilo ND. Free radical scavenging activities of naturally occurring and synthetic analogues of sea urchin naphthazarin pigments. Nat Prod Commun. (2012) 7:901-4. doi: 10.1177/1934578X1200700725

43. Pastrana-Franco OJ, Santafé-Patiño GG, Quirós-Rodríguez JA. Antioxidant activity of the sea urchin Mellita quinquiesperforata (Leske) and identification of its major lipids compounds. Actual Biol. (2016) 38:14-22. doi: 10.17533/udea.acbi.v38n104a02

Conflict of Interest: The authors declare that the research was conducted in the absence of any commercial or financial relationships that could be construed as a potential conflict of interest.

Publisher's Note: All claims expressed in this article are solely those of the authors and do not necessarily represent those of their affiliated organizations, or those of the publisher, the editors and the reviewers. Any product that may be evaluated in this article, or claim that may be made by its manufacturer, is not guaranteed or endorsed by the publisher.

Copyright (C) 2021 Marzorati, Martinelli, Sugni and Verotta. This is an open-access article distributed under the terms of the Creative Commons Attribution License (CC $B Y)$. The use, distribution or reproduction in other forums is permitted, provided the original author(s) and the copyright owner(s) are credited and that the original publication in this journal is cited, in accordance with accepted academic practice. No use, distribution or reproduction is permitted which does not comply with these terms. 